\title{
Confronting Dominant Whiteness in the Primary Classroom: progressive student teachers' dilemmas and constraints
}

\section{Sarah Pearce}

\section{Introduction}

Concerns about beginning teachers' capacity to address issues of diversity in their classrooms appear to be growing across the UK, USA, Canada and Australia (Aveling, 2002; Levine Rasky, 2001; Hyland, 2005). In the UK the Newly Qualified Teacher Survey documents new teachers' attitudes to aspects of their training and new posts. It reports slow progress in how ready new teachers feel to work with minority ethnic students year on year, and remains low at 42\% (TDA, 2009). Qualitative studies support this worrying picture of new teachers who are uncomfortable dealing with diversity in the classroom (Hagan and McGlynn, 2004) or who reject the need for any particular focus on race and racism (Jones, 1999, Solomon, 2005). Despite this generally grim picture, there is evidence that socially aware, self critical new teachers continue to enter the classroom, and to find ways to teach which address issues of racism and difference.

There is some consensus that the reason such teachers remain rare is the narrow range of backgrounds from which teacher candidates are drawn (e.g. Levine Rasky, 2001, Jones, 1999). Those new teachers who see it as part of their role to teach for diversity and address inequity tend not to conform to the traditional model of the primary school teacher, who is seen as young, white, middle class, female and the product of a relatively successful education (Haberman, 1996). In recent years it is student 
teachers' 'whiteness' that has been a focus of research (e.g. Solomon, 2005; Hyland, 2005; Aveling, 2006; Picower, 2009).

\section{Whiteness and Teachers}

These empirical studies are informed by critical whiteness theory, an approach which seeks to deconstruct whiteness as a historical and social category to reveal how it works to retain its elite status in part through its ability to seem invisible or neutral, at least to those with white skin (e.g. Frankenberg, 1993). Thus, in the many recent studies of white teacher candidates' attitudes to race a recurring finding is the students' desire to resist the idea of whiteness as a privileged racial identity, and to minimise the issue of race inequity through appeals to individualism and meritocracy (e.g. Levine Rasky, 2000, Solomon et al, 2005, Picower, 2009).

Working as a white teacher educator with students on issues of race and schooling, I recognise these defensive strategies, and the guilt and resentment that appear to provoke them. But I am also concerned about the direction in which the accumulation of such studies may take us as teacher educators. First, while many white student teachers do seem to resist analysing their own assumptions and the impact of their own racial identity on their attitudes and behaviour, there are also those willing to admit that they are confused (Ringrose, 2007), and others who show considerable awareness of the different effects of racialisation on themselves and others (e.g. Levine Rasky, 2001). An over-emphasis on the most conservative category of students may contribute to a perception of white teachers as only ever racist or power evasive. This in turn makes it more difficult for white teachers to develop progressive 
anti-racist professional identities. Second, a narrow focus on white students' struggles neglects important and illuminating work that might be done to understand how students from minoritised backgrounds grapple with whiteness. It has been noted that the lack of work in this area retains whiteness and white resistance at the centre of the debate, and means that the perspectives and priorities of participants from outside this group are seldom considered (Ringrose, 2007).

\section{Understanding Progressive New Teachers}

This study seeks to add some differentiation to the common depiction of new teachers as white and resistant to the more radical implications of cultural pluralism. It focuses on the experiences of student teachers, from a range of ethnic backgrounds, who have some understanding of the part that whiteness plays in maintaining power and privilege in the hands of an elite, and who want to teach in a ways that challenge white norms.

There are a few studies which identify beginning teachers who practice the kind of progressive pedagogy outlined above. Ladson-Billings' US study of eight new teachers from a range of ethnic backgrounds identifies three key characteristics of progressive teachers: a commitment to their students' academic achievement, an understanding of the significance and complexity of culture in the learning process, and an awareness of the wider socio-political context in which pupils are located (Ladson-Billings, 2001). Levine Rasky's study of a group of new teachers in Canada (2001) identified a similar set of characteristics. There do not appear to be any similar studies of progressive new teachers in the UK. My own small scale study of practicing UK teachers from a range of backgrounds, and Osler's larger study of 
experienced Black British teachers both support one of the key findings of both Ladson Billings and Levine-Rasky: most of the teachers saw their work as a sociopolitical activity, and one in which a key concern was to enable the minority ethnic children they taught to achieve despite the racism they knew they would face. (Pearce, 2005; Osler, 1997).

The findings in this article support previous research which highlights the difficulties any new teacher may face in negotiating institutional norms and inter-personal relationships in the very early stages of their careers (e.g. Jones, 2005). But they also suggest that if we want to understand the role of individual teachers in perpetuating educational inequality more attention needs to be paid to the personal and institutional constraints teachers face when they seek to take a more egalitarian approach to their work. Writing in 2001, Ladson-Billings suggested that the key agents for change in favour of more equitable schooling practices were likely to be new teachers, not Government institutions or legislation. More than a decade on, there are two reasons why a focus on individual teachers and their schools may be even more urgent and necessary. First, in the current political and economic climate, there is little likelihood of new legislation to promote race equality. In England and Wales, early evidence of this is provided by the recently published revised standards for Newly Qualified Teacher Status, which has removed all references to race equality and ethnic diversity (Department of Education, 2011). Second, in the UK, as elsewhere, the Government has indicated its desire to see a shift away from higher education and towards schools as the main providers of initial teacher education. In this context a focus on how schools as institutions support new teachers is clearly important. 


\section{The study}

The data presented in this article are drawn from an ongoing longitudinal study of a group of nine teachers, beginning in their final year on a primary BA(Ed) course in London. Most of the group members are now in their fifth year of teaching. The overall aim of the project is to examine what individual and institutional factors enable or inhibit new teachers in developing an approach to teaching that addresses race inequity and ethnic diversity. In this, the first of a series of articles, I focus on the teachers at the very beginning of their careers. This was a time in which their lack of experience and low standing among colleagues in their placement schools meant that inhibiting factors were far more prominent than enabling ones, though this changed somewhat, for most of the participants, as they gained in experience and status in their first and subsequent posts. Their developing confidence and ability to enact their progressive ideas in their classrooms will be the subject of future articles.

In terms of ethnicity the group was relatively diverse: five of the participants described themselves as white British, two had African-Caribbean backgrounds, one was from a Somali background, and one had a mixed white British-Greek Cypriot heritage. They were all female, and aged between their early 20 s and early 40s. All but one of the women had been born and brought up in London, and identified themselves as being from a working class background. They were voluntary participants, drawn from a humanities course I had taught them in the final year of their BA(Ed) course.

The data were collected mainly through one to one semi-structured interviews. The initial interview, held before the participants' final school experience, established 
each of the participants' social and ethnic backgrounds, educational experiences, general attitudes to teaching, and to ethnic diversity. A second interview was then held immediately after the final school experience and this followed the pattern of all subsequent interviews, which were held on an annual basis at a place of the participant's choosing. This was often in my office at the university, but sometimes in a café or at the participant's home. Each interview lasted between 40 and 90 minutes.

The methodology of the project was influenced by narrative approaches to understanding teachers' perspectives, which seek to explore how teachers' individual experiences and perspectives link to wider social and political issues, without minimising the importance of either (Beattie, 1995, Erben, 1998). My questions focused on eliciting descriptions of events and conversations related to ethnicity and culture, and participants' reflections on these. Stories tended to centre on memorable incidents or conversations with individual children or colleagues, and issues arising from planning or teaching the curriculum. Participants were also asked to keep a journal to supplement interview data, but pressure of work meant that only three members of the group managed to do so. I sent each individual transcript to the interviewee for verification. I then carried out a content analysis of each transcript using NVivo software to generate codes and categories. As transcripts were added each year I was able to identify patterns and shared concerns across the group, as well as to trace individual career trajectories.

This article draws on data from the second round of interviews, just after the participants' final teaching practice. It also makes use of one student's journal, written during the practice. Focusing on the curriculum, it examines what happened when 
some of the students challenged unexamined white norms in the material they were expected to teach. It is important to note that for three of the nine participants, perhaps significantly all teaching the youngest children, three to five year olds, this was not an issue. They felt that the curriculum they taught did address issues of race and culture to a degree which was appropriate for the children in their classes. A third group of three participants expressed some misgivings about the monocultural approach to the curriculum taken by their host teachers, but took a pragmatic decision to conform. Maria's story is told as an example of this stance. However, in keeping with my aim in this article to examine in some detail what happens at an individual and institutional level when progressive student teachers mount a challenge to the status quo, my focus here will be on the stories of the three students who spoke out against the taken for granted dominance of whiteness in the curriculum.

\section{Culture, Power and the Curriculum}

Informed by critical whiteness theory, the curriculum in English schools can be seen as a key site for the protection of hegemonic notions of whiteness, and the exclusion and thus the subordination of other cultural practices and artefacts (Tomlinson, 2008; In England the National Curriculum was explicitly conceived as a way of preserving and transmitting a set of values associated with a Conservative white British elite (Blair and Cole, 2000). The lack of attention to racism and cultural diversity in the National Curriculum can be seen as one indicator of the continuing dominance of whiteness at government level, where the voices and experiences of minoritised groups are simply not seen as important enough to necessitate a redrafting of the curriculum (Gillborn, 2005) despite high level calls to undertake such a project (most recently MacPherson, 1999 and Ajegbo, 2007). 
Such an analysis draws together aspects of two approaches to ethnic diversity which have historically, in the UK (as in some other parts of the West) been in conflict. In the 1980s multiculturalists' belief in the curriculum as a medium for promoting intercultural understanding was criticised by anti-racists, who argued that this approach would make no impact on the key issue of unequal power relations. Few would argue today that racial inequity will be effectively addressed without wide-ranging structural changes. But at the level of the classroom, it still seems important to find ways of addressing culture and identity, and to avoid the binary black-white conception of racism which underpinned some anti-racist approaches.

A more recent approach to multiculturalism, sometimes called critical multiculturalism (May, 1999) draws on work by whiteness theorists, among others, to show how discussions about culture and difference must include analysis of white groups, so that the neutrality and invisibility of whiteness, and thus its unacknowledged dominance, is challenged. This entails, 'a recognition that all speak from a particular place, out of a particular history, out of a particular experience, a particular culture, without being contained by that position (Hall, 1992, p.258). In the hands of skilled and committed teachers, the curriculum can provide a space in which such learning can take place, so that aspects of hegemonic white culture are examined alongside, not pre-eminent among, other cultures. This makes it possible for both culture and power to be opened up as topics for discussion, in contexts which are meaningful for children.

\section{Maria: policing the monolingual classroom}


One example of the dominance of white norms in England may be said to be the deficit discourse associated with speakers of English as an additional language (EAL). Ainscow et al (2007) have pointed out that, in both government policy documents and in Initial Teacher Education, EAL is usually constructed as synonymous with special needs. The view that children whose first language is not English are best served by learning in a monolingual English environment remains common, despite evidence of the cognitive and social benefits of maintaining one's first language alongside the development of a second or third (Cummins, 1996). Of the nine students in the larger group, only one believed themselves to be placed in a school where a multilingual approach was understood to be beneficial, and was integrated into classroom life. Much more common was an assumption that the teaching of non-English speakers should be geared toward the rapid acquisition of English, to enable them to access the mainstream monolingual teaching environment as quickly as possible (Bourne, 2001). It is important here to clarify the importance of geographical context in understanding how whiteness operates. There is of course no simple correlation between whiteness and monolingualism. But in the context of England, as in the USA and Australia, for example, it is because the dominant, white, group is monolingual that multilingualism is seen as problematic.

Maria was a white British student in her twenties. She had been brought up in a working class, multi-ethnic area of London. At university, she had been taught that bilingualism is both socially and cognitively beneficial. As a result, she faced a dilemma when she was placed in a school with a policy of not allowing children to speak their home languages in the classroom. She taught a class of 6-7 year olds in an 
inner-city school with an almost exclusively Bangladeshi intake. Maria was thoughtful about the advantages and disadvantages of this policy decision:

MG: would my parents have been happy with that if my first language wasn't... would they have been ok with me only speaking the sort of common denominator language that [hesitates]

SP: What's the answer to that question?

MG: Hmmm...I don't know. I think they would have perhaps...see it's difficult isn't it?[ ] Because at the end of the day you live in a society where you know you need to speak English and that's what's accepted and... but then surely [sighs] you still need to value the other... and you know it's so hard for me because all the learning we've done on our course, seeing all the evidence that says that children that have more than one language and that continue to develop their language alongside English, and all the positive effects it has and how well children do, so it's very difficult for me to not see it in practice and to kind of say well...because the children are achieving, but then would they be achieving even more if they were allowed to speak their own language? [ ] I still feel, sometimes when I say to a child, 'oh you shouldn't speak Bengali in class', part of me does...you know? I feel a bit...[laughs] I don't know what it is, I just feel like I shouldn't be saying that. But you just follow the school policy.

It is important to note here the influence that the interviewer-interviewee relationship may be having on Maria's comments: her somewhat disjointed reply may indicate her discomfort at having to justify the schools' monolingual policy to her former tutor 
who, she is aware, disapproves of it. It may also suggest that this is the first time Maria has considered the controversial nature of the policy. Yet she is aware of the very real dilemma she is in: the school's policy does seem to be working, in terms of English acquisition, and as a student she is anyway in a weak position to challenge such a policy. On the other hand, she feels uncomfortable when she is placed in the position of having to ask a child not to speak their home language, and shows both emotional and intellectual understanding of the possible detrimental effects this may have on their personal and cognitive development.

The monolingual policy of the school was a response to the local authority's requirement that it improve its test results, itself reacting to pressure from the government:

I just feel that it's very much focussed on their learning and their achievement being in a school in [names authority] and targets being such a big thing. And it's all about, you know, getting the levels- especially in maths and English.

She noted, however that in teaching Religious Education a different approach was adopted. The focus here had been on talking about the children's faith and how they practiced it:

And it was great because they knew so much, and even some of the lower ability children, they were so confident because...they could suddenly contribute and some of the children who were normally a bit shy and wouldn't contribute to discussions, they were like, 'oh I know so much about this because this is what I do every day, and this is part of me...' so I 
felt in RE some really, really good stuff came out and sort of just their writing as well. You know, it all follows on. If you're doing lots of discussion and talk the writing's really good

Maria notes that levels of confidence and motivation rose during this topic, because, she suggests, the children felt they knew about the topic, and wanted to discuss it. Approaches which draw on children's existing knowledge and experience, the bedrock of primary teachers' practice for decades, have become increasingly rare in England, even in infant classrooms, as a result of the National Curriculum (Walker, 2005; McNess et al, 2003). Yet Maria notes that the quality of the children's talk and therefore their writing was higher than usual as a result of the children's feeling ownership of, and personal interest in, the topic.

Maria's experience of working within tight restrictions was a result of local authority priorities, in turn a response to pressure from successive governments which have demonstrated little interest in pushing for the reforms which have been shown to enable children from minority groups to achieve and thrive in school (Parsons, 2009, Gillborn, 2005). While she remains ambivalent about the monolingual policy of the school, she is clear in her belief that a curriculum which acknowledges the children's interests and experience is more likely to result in greater learning than one drawing on materials and references of no relevance to them. Her experience echoes that highlighted in previous research in which teachers felt obliged to put into practice policies which they did not believe to be in the best interests of their pupils (Pearce, 2005, McNess et al, 2003). 
However, a more complex picture emerges through the experience of three other members of the group. Here it is not impersonal institutional policy but individuals who appear to defend or protect dominant white norms.

\section{Farida: challenging the white standpoint}

Farida was a Londoner in her twenties, from a Somali background. She was a committed Muslim and wore a hijab, a scarf which covered her hair and neck. Her final placement was in an inner city school in which most of the children came from African-Caribbean, African or Portuguese backgrounds. She recorded her approach to her assigned topic of 'Victorians' in her journal:

I wanted to make this topic accessible to the majority of the class, who are black. My research was made and in my first lesson I wanted to include some photos of famous black Victorians. Some teachers saw my photos while I was laminating them and so I explained who they were and why I was using them. I thought that as I was in a multicultural school that this was something that would appeal to many teachers- however I only sensed awkwardness. I'm sure this was not paranoia- but all of a sudden I felt like I was guilty of pushing for a political course.

Farida begins her work with the assumption that what she is doing is simply good practice in terms of multicultural education. She is trying to show where the children in her class fit in to the history she is teaching them. It is only when other teachers in the school are less than positive about her innovation that she begins to see her project in a different light: she is being 'political'. She is questioning existing power relations by challenging the unspoken dominance of white culture in this very traditional school topic. 
At interview Farida described how she encountered more direct resistance when she asked her white class teacher if she could build on the teacher's idea of a timeline for her history topic, by using the notation BCE (Before Common Era) and CE (Common Era) instead of the usual, BC/AD notation, which is derived from the Christian tradition. The $\mathrm{BCE} / \mathrm{CE}$ format is preferred by secularists and those not wishing to give primacy to Christianity in a multi-faith context:

I have to be respectful because this isn't my classroom, so I asked the teacher. I said, 'you know what, this is the issue here, you know, and what is the school's stance on that?' Before I could even finish off the sentence it was just, 'No: $B C /$ AD.' I thought that was really interesting because ...it's a community school- there's no, it's not a particular faith school... so I just thought, OK, and that made me feel really uncomfortable, because I was just thinking like, did I just overstep...? [rueful laughter]...because I was thinking that in this classroom where you've got a mix of children, different backgrounds, different religious backgrounds as well, I'm just thinking, they may not realise this, but things like this can actually have an effect on them, you know-subconsciously, in the sense that these are the messages that they're getting.

It is not possible now to probe the reasons for the class teacher's unequivocal rejection of Farida's request. It may be that she knew the school policy on this matter, and knew that it would not be acceptable. It may be that she made the decision on the basis of her own personal views, or that she felt threatened by Farida's wider knowledge. Certainly, Farida's journal entry concerning other colleagues' reactions to her use of photos of Black Victorians suggests that the school as a whole was not in 
the habit of ensuring that their resources addressed the issue of diversity. The lack of discussion and justification does suggest that, either at an institutional or an individual level, white norms were unreflectively imposed in this multi-ethnic classroom. Again, it is important to note that, though of course Christianity is not a white religion, I argue that it is because Christianity is one aspect of hegemonic whiteness that it was defended here.

The sense of discomfort Farida felt may have inhibited many students from suggesting further changes, thus shutting down innovation and diversification. But of all the participants in the project Farida was the most determined to offer a multicultural curriculum. She described how, despite this incident, she continued to try to take a more inclusive approach to her history topic. This time she encountered resistance from the pupils themselves. She explained that she had assembled a range of images to introduce the topic of Victorian Britain, deliberately including some of Black figures from the time, including one of Arthur Wharton, the first Black British footballer.

I just wanted to see what the children would make of it. Some of them didn't even acknowledge the fact that they were Black [laughs]. Especially with the footballer, he's standing there with an Afro, and he's obviously not white... with some of the kids, it was nothing, nothing to them. So the few kids that I did sort of say, 'oh d'you know what, where do you think he would come from, I know he's British, but where do you think he would originate from? Do you think he was a white man, do you think he was Asian..?' 'He was white.' And I was like, 'Look!' [acts out her incredulous reaction] you know, 'Where have you seen a white man with an Afro like that?' And I was just thinking, to me that just 
reinforces that idea that it's those subliminal messages that they receive, you know, that has that effect on them: it can't have been a Black person.

Farida's view is that the monocultural curriculum the children have been used to, and the lack of open discussion of ethnicity, culture, and of home life generally in the school, made them uncomfortable with discussing difference in the classroom:

For me this is a really important...if I was to have my own class, this is something that...talk of like, private, you know, your home life and things that you do, traditions, that's something that I would always bring up with the kids.

Like Maria, Farida notes the importance of using the children's home lives as the basis of work in the classroom, in contrast to a focus on the delivery of a homogeneous curriculum which has become increasingly common in English primary classrooms. She expressed her frustration at how few opportunities there were to draw on children's personal lives, one small exception being getting children to say good morning in different languages:

Even that when I first started it was just...The excitement, it was just...total behaviour management, it was just, 'oh my God why did I do this? They couldn't handle it. I mean now they're getting the hang of it, you know. They ask me, you know, 'how do you greet? How would you greet in your language?' And I said, well, we don't have a specific greeting, but because we are Muslims, we would just greet each other by saying 'assalam alaikum' and 'wa alaikum assalam'. Told them what it meant. And I see how in a sense things kind of opened up, and they're just looking around them. And I see that 
sometimes what they tend to do is say, like, greet me in Portuguese, or greet me in each other's languages, so they're sharing it

\section{Natalie: who counts as British?}

Natalie also encountered opposition from her class teacher mentor when she attempted to broaden the conception of what it meant to be British for her class of ten year olds who were studying the history topic 'Britain Since 1930'. The school was in the suburbs of London and had a mainly white intake. Natalie was in her late twenties and had a Caribbean heritage. All of the teachers in the school, including her class teacher mentor, were white. As part of the topic, each child was asked to choose an image for the front cover of their workbooks. To help the children to decide, the teacher often offered suggestions:

He was saying, 'oh you could do Churchill, you could do the Beatles, you could do this, you could do that'. And every time he had that conversation I kept putting my hand up and saying, 'or Bob Marley' [laughs]. It's like he refused to acknowledge that it was part of the history. And even though... he still had the British roots...I couldn't understand what his point was. Bob Marley's music made an impact. All children know Bob Marley, they...it's a universal thing. But he kept asking the same question, 'oh is it...you know...is he British?' And I had to keep telling him, 'yes, he was.'

Natalie is frustrated by what she sees as her class teacher's apparent unwillingness to broaden the definition of Britishness which he is imposing on the children. The topic also covered dance music in the period: 
They kind of did waltz, and they wanted to do dance and punk and rock and Beatles and I said, you know, and I was going to go, because l've got old Soca music and calypso music... but I couldn't be bothered to...you know when it's like-it's not my class and I can't really have the impact that I would like to have on them, and they wouldn't even know what the music was and there were some really...you know like boyish boys who would do anything for a rise, and I thought, I'm just going to go along with the teacher, but it was UB40 and Simply Red, and of course they are British, but where did their music originate from?

Natalie is again critical of the choices the teacher made in terms of the types of music he chose to include in the topic: waltz, punk, rock and the Beatles all being considered to be white music. Her point is that Black music had a profound impact on music in Britain in this era, opening up the possibility for the children to learn about how other cultures have been incorporated into British life and art, which was rejected by the teacher. Natalie's response to this rejection is also important here. She felt that she herself could have been used as a resource to facilitate this learning, but felt inhibited from offering her knowledge, both by the teacher's lack of interest and because she suspected some of the pupils would react negatively to it. Her use of the phrase 'couldn't be bothered' points to the effort she feels it would have taken to challenge this situation, and perhaps also to a sense of disillusionment and disengagement she felt as a result. Natalie repeatedly refused to say that she had definitely experienced racism on her school placement, though this incident, and others she related, do point to the very subtle and unspoken ways in which minority ethnic teachers may feel that their contribution is undesirable, particularly if it challenges individual and institutional norms. 
Natalie's other key criticism of her class teacher was his unwillingness to draw the children's home lives into curriculum work. She maintained that this issue went 'beyond race', but she was particularly concerned by his lack of interest in the different cultural backgrounds of some of the children in his class:

I didn't notice any sort of encouragement for the Hungarian or the French child to use their language, or even for the half Asian guy to explore or express his sort of side. ...there were no French words around the class, there were no Hungarian words, there was just nothing. It was like it wasn't there... And the boy went to Hungary for two weeks...so he was in a Hungarian school for a week. But there was no sort of, 'oh, bring your work back let's see it,' There was no, 'can we email the school?'

In criticising her class teacher, Natalie sets out a vision of the kind of teacher she hopes to be: she wanted to draw on the children's knowledge of other languages both to support their own development and to enrich the other children's experience. She wanted to welcome children's experiences outside school as valuable material for use inside school, and use opportunities to make global connections. Like Farida, she acknowledged that time pressures and Government priorities made this kind of teaching difficult:

I do feel we have a lot on us, in terms of planning and marking ... but there's no reason why we can't put ourselves beyond that and ...connect with the children. But then you know at the beginning of this course I remember someone saying they're not really interested in anything other than the maths and the English, why do you need to cover the cultural side and the 
personal side? ... That is not what's monitored, is it? It's English and maths, that's all they care about... But then you can't keep using the excuse of paper and things to get in the way of how you get to know your children.

Natalie knows that the very tightly structured and closely monitored system in which teachers in England currently work is a strong deterrent to the kind of personalised teaching which she advocates. But she suggests that it is not just these institutional factors which prevent a more culturally sensitive approach to classroom work, but the fact that some teachers' own individual philosophies are in accordance with this deracialised Standards-led discourse. But she continues to uphold her own belief in the fundamental duty to focus on the children in her care, rather than on curriculum delivery.

\section{Debbie: orientalism in the classroom}

Debbie also encountered the unreflective imposition of white norms during her final school practice. Her placement was with a class of 6-7 year olds in a suburb of the city which had a ninety per cent white intake. Most of the other children in the school came from African-Caribbean backgrounds. Debbie herself was in her thirties and from a white British background. In her first interview she described how she had adopted an anti-racist position from an early age and had worked for social services and as a nursery nurse in multi-ethnic settings before training to teach. She recounted a conversation which took place between her and the two white class teachers in her year group at a meeting to plan a project on India: 
The other Year 2 teacher was going, 'oh what are we looking at in India this week?' and gods were mentioned and she sort of said, 'oh well they'll bloody worship anything over there won't they?' And I was [mimes shock] 'oh my god I can't believe what I'm hearing'. She's going, 'oh I had to teach...the Ganesh story the other day. It's so violent! What are they teaching the kids that for?' And I sort of went, [adopts self-mocking high voice] 'oh yeah but what about that story in the Bible where, you know, they threaten to cut the baby in half, and King Herod, you know, you can find it wherever you look'... It shocks me that people will still openly...even if people think that, that they still think it's ok to say it in front of other white people and assume that other white people will have the same opinion and not realise that that's not ok to say... I used to challenge things like that quite forcefully and quite well I think and I don't anymore. I don't know if that's because I was a student...I mean what could I do? I was a student.

Debbie brings to light here a very clear example of a white teacher demonstrating how whiteness can inform an unreflective standpoint: she criticises another culture without recognising that such criticism might equally be made against an aspect of her own cultural heritage. Despite Debbie's self-criticism, she does challenge the invisible, neutral status of white cultural norms, pointing out that stories from the Bible are often blood-thirsty in a similar way. As Debbie suggests, perhaps the most disturbing aspect of the teacher's views is her assumption that what she said would be acceptable to the other members of the group, both of whom were white. Again, Debbie's refusal to collude with her senior colleague's assumptions about their shared values based on their shared membership of a privileged group, points to the possibilities open to students who, like Debbie, have a clear commitment to and understanding of the issues. Nevertheless, Debbie describes herself as disappointed in the mildness of her 
challenge, which she explains as being a consequence of the weakness of her position as a student teacher, a guest in her host school. This was a concern raised by other students in the group when faced with similar issues.

The narrow attitude these remarks reveal may also be seen in both the general approach to teaching about India, and in one particularly telling incident while the topic was in progress. Debbie felt that the topic as a whole took a very conventional colonial view:

It was very much, you know, 'there are poor people in India, people live on the streets,' you know that real stereotypical, that's what the project was focused on: 'It's really hot and look at these pretty colours that they wear on their saris' and it really, really did not do more than scratch the surface.

In adopting this approach, the teachers did not offer the children any challenge to possible misconceptions they may have had about Third World countries, or begin to develop their understanding about historical and contemporary relationships between countries, or about the nature of different cultures. There was little attempt to examine India through the eyes of Indian people.

This stance, in which another culture is judged according to white norms, may also be seen in a key decision which was made in the course of the topic, ironically concerning the only aspect of the topic which was initially controlled by an Indian teacher, who taught dance: 
It was really fun, and you know and some of the boys who, you wouldn't imagine would want to do dancing really looked forward to it every week ...but the teacher was teaching them Bollywood style dancing and the school said to her, 'no, sorry we asked for Indian dancing' and what they wanted was their image in their head of Indian dancing, because they were doing a presentation of it at the end of year concert. 'We want, you know, what we perceive as Indian dancing,' is really what they were saying. 'We don't want this Bollywood stuff'. And that actually is India now, that's India today isn't it... And the teacher said she thought it was a bit too sexy, which I didn't at all. But no, she was told in no uncertain terms to change it.

Debbie relates an incident in which the children were exposed to an authentic aspect of a different culture, and that it was seen as a very positive experience for her mainly white class. But her perception is that even this very moderate form of multiculturalism was halted because what the children were doing did not conform to the teachers' stereotypical image of Indian dancing. It is not clear whether this was a decision made at senior management level, or by an individual teacher. Either way, despite the fact that the dance was choreographed by an Indian teacher, it was a white perception of Indian culture that counted.

In reflecting on what she had learned from her involvement in the India project, Debbie spoke about how her attitude to teaching about other cultures had changed. Before the placement, she said that her support for multicultural education had, 'always been very theoretical'. Now she was very conscious of how her own identity as a white teacher would inevitably influence her teaching: 
Much more than anything else it's caused me to think, how can we make multiculturalism or...I don't know I don't even know what the word is, but a non-European white bias, how can we stop that, and do it really well, in the curriculum? I don't know. I don't know what the answer is to that. I don't know if I would do that really well. I don't know if I would never do it well because I'm white. I really don't know.

Her words convey her sense of frustration at her powerlessness to change the course of the India project, as well as her fears about how far her whiteness will restrict her understanding in the future.

\section{Defending the white curriculum?}

In each of the classrooms described above, the curriculum provided can be said to be both informed by and supportive of white cultural values and norms, to the exclusion of the experiences and perspectives of other cultural groups. In Maria's case, it could be argued that her actions, and those of the other teachers in the school, were circumscribed by wider pressures from without: the authority's drive to improve test scores above all else, in response to pressure from the Government. Her experience illustrates why it is often argued that while such priorities exist, individual schools and teachers should not and cannot be held responsible for the persistence of inequalities in the classroom, and that change must begin at the level of Government (Parsons, 2008; Gillborn, 2005). But the three other examples offered here suggest that some teachers took a stance which cannot be explained as a reluctant response to legislative requirements. Their actions defended a narrowly conceived curriculum, informed by perceptions and cultural experiences drawn exclusively from a white standpoint. 
In seeking to offer a more nuanced and compassionate understanding of beginning teachers' experiences in struggling with dominant forms of whiteness, I am conscious of the danger of appearing to offer up a new category of victim in their place:

experienced white teachers. There are two points I would like to make to mitigate this risk. First, it is important to acknowledge that all teachers can only draw on a limited range of experience when engaging with other cultures: we all struggle with difference. But when we, as white teachers, demonstrate a limited cultural repertoire our position as members of the dominant ethnic group can act to insulate us from consciousness of our restricted understanding. There are few among us who will challenge our thinking, and we will rarely be forced to listen.

Second, there is no evidence to suggest that, in blocking attempts to adapt the curriculum, the teachers concerned were consciously defending a white curriculum. It may be that they were simply rejecting a challenge from a junior colleague to the way things had always been taught. But these instances offer useful vignettes of how institutional racism really works. In Britain, the notion that outcomes, not intentions, are what matter in defining racism only entered mainstream debate with the publication of the MacPherson Report (MacPherson, 1999). There is evidence, however, that this key aspect of the nature of racism is still poorly understood among education professionals, who still hold onto the view of racism as something more overt and aggressive (Parsons, 2008; London Development Agency, 2004). In assessing the likely outcome of these teachers' refusal to accept a broader range of curriculum material, as opposed to their intentions in doing so, it is clear that minoritised pupils will lose an opportunity to learn about a wide range of cultures and 
perspectives, including at times their own and, alongside their white British classmates, to see them valued and normalised alongside the familiar white European canon.

\section{The beginning teachers' values and priorities}

Each of the four beginning teachers described in this article was critical of the attitudes to difference they confronted on their placements. There is evidence to suggest that this attitude may have been largely a consequence of the students' individual biographies. Two of the students, Farida and Natalie, were themselves from minority ethnic backgrounds, and were highly aware of the issue of dominant whiteness before beginning their practice. All four described themselves as working class, and had been educated in multi-ethnic urban schools. Natalie and Debbie were both older than the average for student teachers. Each of these factors has been identified as indicative of teachers who are more likely to bring a socio-political consciousness to their teaching (Haberman, 1996). A key characteristic of such teachers is their first hand experience of disadvantage. Their ability to recognise, criticise and at times challenge dominant white norms in the schools they served offers support for Ladson-Billings' optimism that new teachers can provide more socially just approaches in the classroom, and can at times challenge more established colleagues' assumptions and practices.

While the four students had different views on many issues, they appear to share one key pedagogical principle. They all believed that it is the task of the teacher to provide a curriculum which acknowledges children's existing knowledge and experience, and to draw the children's personal and family lives into classwork, so 
that school and home life are not seen as separate, or even in conflict. This principle demands that, for example, in Maria's classroom, Islam is a regular topic for discussion, and in Farida's the presence of Black people in Victorian Britain is acknowledged. It is from these fairly traditional, and therefore fairly safe, starting points that broader notions of culture and ethnicity, status and power, and the many similarities and differences between people, can become normal and natural topics for classroom debate.

All four students were strongly aware that this principle was not put into practice in the classrooms in which they were placed, though they differed in their analysis of why this might be. Maria felt that she, like her teacher, was simply forced to implement a strategy to improve attainment which involved a very narrow focus on maths and literacy with little attention paid to children's lived reality. Farida, Natalie and Debbie felt that their teachers uncritically 'delivered' the monocultural National Curriculum, seeing no need to adapt it to address the interests of their pupils or the wider needs of a diverse society. Farida and Debbie were both of the belief that their teachers' whiteness was part of the reason for their unwillingness to engage with difference. Natalie was reluctant to point to race as the motivating factor in her teacher's actions. She explained her teacher's resistance to broader definitions of Britishness, and his narrow view of what was appropriate talk in the classroom, as stemming from his different, and in her view uncaring, perception of his role, and his unwillingness to engage with the children. Nevertheless, it should be noted that maintaining social distance between oneself and one's pupils has been highlighted as a feature of unreflective white teachers' practice (Levine Rasky, 2000, Pearce, 2005). 


\section{Conclusion}

There is ample evidence to suggest that in England, as elsewhere, the curriculum in primary schools is dominated by hegemonic notions of whiteness, and little understanding among many teachers of what a more inclusive curriculum might look like (Ajegbo, 2007). It must be emphasised that individual teachers cannot be blamed for a monocultural statutory curriculum put in place by, and at times heavily resourced by, Government, and that the most effective site for change would be at the level of Government institutions and legislation (Gillborn, 2005). But I continue to argue that there is much for individual schools and teachers to do in understanding how their practices might uphold white norms, and prevent other perspectives from becoming embedded in the curriculum, with the result that all children, from both minority and majority ethnic groups, are unable to develop a positive sense of identity and an informed understanding of their own place in the world.

The article offers examples of some of the issues student teachers may confront in challenging white norms in the curriculum, but suggests that both minority ethnic and white teachers who have a commitment to equity and social justice may be willing to grapple with these issues. It adds to the body of evidence on possibilities for change: when socially aware, reflective teachers from a range of ethnic and socio-economic backgrounds enter the profession there is potential for debate and discussion about issues of race and difference. Such debate could lead to greater self awareness among existing teachers and ultimately to changes in policy and in practice. While the current study suggests that student teachers on placements are perceived as too junior to influence practice, the fact that these teachers did maintain their commitment into their first teaching post, offers some cause for optimism. Whether this commitment is 
supported or hindered in practice by the schools in which they find themselves is a matter for further research. 


\section{References}

Ainscow, M., Conteh, J., Dyson, A. and Gallanaugh, F. (2007)

Children in Primary Education: demography, culture, diversity, inclusion. Primary

Review Research Survey 5/1, (Cambridge: University of Cambridge Faculty of

Education)

Ajegbo, K. (2007) Curriculum Review: diversity and citizenship (London, HMSO)

Aveling, N. (2002) Student Teachers' Resistance to Exploring Racism: reflections on 'doing' border pedagogy, Asia-Pacific Journal of Teacher Education, 30 (2), 119-130 Aveling, N. (2006) 'Hacking at our very roots': rearticulating White racial identity within the context of teacher education, Race, Ethnicity and Education, 9 (3), 261-274 Beattie, M. (1995) New Prospects for Teacher Education: Narrative Ways of Knowing, Teacher and Teacher Learning, Educational Research, 37 (1), 53-70

Blair, M. and Cole, M. (2000) Racism and Education- the imperial legacy in: M. Cole (ed.) Education, Equality and Human Rights (London, Routledge/Falmer)

Bourne, J. (2001) Discourses and Identities in a Multi-lingual Primary Classroom, Oxford Review of Education, 27 (1), 101-114

Cummins, J. (1996) Negotiating Identities: education for empowerment in a diverse society. (Ontario, California Association for Bilingual Education)

Department for Education (2011) Teachers' Standards. Available at: http://media.education.gov.uk/assets/files/pdf/t/teachers\%20standards.pdf (accessed 23 August 2011)

Erben, M. (1998) Biography and Research Method, in: M. Erben (ed.) Biography and Education- A Reader (London, Falmer)

Frankenberg, R. (1993) White women, race matters: the social construction of whiteness (Minneapolis, University of Minnesota Press) 
Gillborn, D. (2005) Education policy as an act of white supremacy: whiteness, critical race theory and education reform, Journal of Education Policy, 20 (4), 485-505 Haberman, M. (1996) Selecting and Preparing culturally competent teachers for urban schools, in: W.R. Houston, J. Sikula, T.J.Buttery and E. Gruyton (Eds.) Handbook of Teacher Education (New York, Macmillan)

Hagan, M. and McGlynn, C. (2004) Moving Barriers: promoting learning for diversity in initial teacher education, Intercultural Education, 15 (3), 243-252 Hall, S. (1992) New Ethnicities, in: Donald J. and Rattansi A. (eds) 'Race' Culture and Difference (London, Sage)

Hyland, N.E. (2005) Being a Good Teacher of Black Students? White Teachers and Unintentional Racism, Curriculum Inquiry, 35 (4), 429-459

Jones, M. (2005) Fitting in, Feeling Excluded or Opting Out? An Investigation into the Socialisation Process of Newcomers to the Teaching Profession in Secondary Schools in England, Journal of In-service Education, 31 (3), 509-526

Jones, R. (1999) Teaching Racism, or Tackling It? Multicultural stories from beginning teachers (Stoke on Trent, Trentham) Ladson-Billings, G. (2001) Crossing Over to Canaan: the journey of new teachers in diverse classrooms (San Fransciso, Jossey- Bass)

Levine-Rasky, C. (2001) Identifying the Prospective Multicultural Educator: Three Signposts, Three Portraits, The Urban Review, 33 (4), 291-318

Levine-Rasky, C. (2000) The Practice of Whiteness Among Teacher Candidates in International Studies in Sociology of Education, 10 (3), 263-284

London Development Agency (2004) Educational Experiences and Achievements of Black Boys in London Schools 2000 - 2003 a report by the Education Commission. Available at: www.lda.gov.uk/upload/rtf/Findings.rtf (accessed 8 July 2009) 
Macpherson, W. (1999) The Stephen Lawrence Inquiry (London. HMSO)

May, S. (ed.) (1999) Critical Multiculturalism (London, Falmer)

McNess, E., Broadfoot, P., Osborn, M. (2003) Is the Effective Compromising the Affective? British Journal of Educational Research, 29 (2), 243-257.

Osler, A. (1997) Black Teachers and Citizenship: researching differing identities, Teachers and Teaching, 3 (1), 47-60

Parsons, C. (2008) Race Relations, Ethnicity and Disproportionality in School Exclusions in England, Cambridge Journal of Education, 38 (3), 401-409

Parsons, C. (2009) Explaining sustained inequalities in ethnic min school exclusions in Eng- passive racism in a neoliberal grip Oxford Review of Education, 35 (2), 249265

Pearce, S. (2005) You Wouldn't Understand: white teachers in multi-ethnic classrooms (Stoke on Trent, Trentham)

Picower, B. (2009) The unexamined whiteness of teaching: how white teachers maintain and enact dominant racial ideologies, Race, Ethnicity and Education, 12 (2), $197-215$

Ringrose, J. (2007) Rethinking white resistance: exploring the discursive practices and psychical negotiations of 'whiteness' in feminist, anti-racist education, Race Ethnicity and Education, 10 (3), 323-344

Solomon, P., Portelli, J.P., Daniel, B., and Campbell, A. (2005) The discourse of denial: how white teacher candidates construct race, racism and 'white privilege', Race Ethnicity and Education, 8 (2), 147-169

Teacher Development Agency (2009) Results of the Newly Qualified Teacher Survey Available online at http://www.tda.gov.uk/upload/resources/pdf/r/results_nqt_survey09.pdf (accessed 19 July 2010) 
Tomlinson, S. (2008) Race and Education: policy and politics in Britain

(Maidenhead, Open University Press)

Walker, A. (2005) Effective Leadership in Multi-Ethnic Schools, part I (Nottingham, National College of School Leadership) 